\title{
LA NEGATIVIDAD EN EL HUMANISMO DE HEIDEGGER
}

\section{NEGATIVITY IN HEIDEGGER'S HUMANISM}

\author{
Javier Pérez Guerrero ${ }^{1}$ \\ Universidad Internacional de la Rioja (España)
}

Recibido:1- 2- 16

Aceptado: 2- 5- 16

Resumen: Este estudio profundiza en el significado de la noción de Nichtung de Heidegger, que se considera como la clave de la auténtica formación humana, y se conecta con la negatividad que encierra el concepto de Bildung en Hegel y la reducción trascendental al ego puro de Husserl.

Palabras-clave: alienación; formación; humanismo; negatividad; trascendencia.

Abstract: This study goes deeply into the meaning of Heidegger's notion of Nichtung, which is considered as the key of the authentic humanistic formation, and it's connected with the negativity that Hegel's concept of Bildung contains and the Husserl's transcendental reduction to pure ego.

Key-words: alienation; formation; humanism; negativity; transcendence.

\section{Introducción}

Emily Dickinson, en su poema $285^{2}$, nos dice de sí misma que ve el mundo nuevainglaterramente (New Englandly). Sin embargo, ser capaz, como ella hace, de reunir las palabras para describir en qué consiste mirar el mundo desde ese punto de vista idiosincrático ${ }^{3}$ trasciende dicho punto de vista. En el caso de Emily Dickinson,

1. (javier.perez@unir.net) Javier Pérez Guerrero nació en Sevilla y se doctoró en Filosofía por la Universidad de Navarra en 1995. Ha sido profesor de la Universidad de Navarra y de la Universitat Internacional de Catalunya, y en la actualidad es profesor de la Facultad de Educación de la Universidad Internacional de la Rioja. Ha publicado libros y artículos sobre metafísica, teoría del conocimiento, filosofía política y filosofía de la educación.

2. Según el orden de la edición de Johnson, T. H. (Ed.): The Complete Poems of Emily Dickinson. Londres: Faber and Faber, 1970.

3. Para comprender el significado que podría tener este perspectivismo vid. Mulder, W.: "Seeing New Englandly: Planes of Perception in Emily Dickinson and Robert Frost" en The New England Quarterly 52/4, 1979, pp. 550-559. 
ver a través de una mirada modulada por el acostumbrado ciclo de las estaciones, por la latitud y la longitud, por lo cercano y lo lejano, por los criterios aprendidos, se convierte en un recurso que puede ser explorado, lo que supone distanciarse de esa mirada. La Dickinson sabe, por ejemplo, que «si hubiera nacido en Inglaterra/ desdeñaría las margaritas». Así, lo que en el caso de otras señoritas de clase acomodada del pueblerino Amherst de mediados del Diecinueve supondría probablemente un localismo rocoso, en el caso de la Loca del Ático se convierte, gracias a una toma de conciencia liberadora, en cauce para su poesía: «la Reina discierne como yo/ de manera provinciana», escribe en ese mismo poema.

Esa toma de conciencia emancipadora en la que alcanzamos una mayoría de edad respecto a todo lo que hemos aprendido de nosotros mismos consiste en dar un paso atrás que es la clave de la formación verdaderamente humana. Vivir de modo emancipado o adulto cualquier identidad asumida o cualquier rol aprendido consiste en dejar de plegarse o acomodarse a ellos y abarcarlos, profundizando en uno mismo. Así considerada, la formación humanizante es una imaginería interior (Bildung) que consiste fundamentalmente en un ahondamiento en la experiencia de sí: un buscar o preguntar hacia atrás (rückfragen) que nos retrotrae, más allá de nuestra raíz, al suelo donde los últimos filamentos de ésta se pierden. No se trata por lo tanto de un proceso acumulativo, sino de una profundización que mantiene la distancia respecto a cualquier experiencia posible de uno mismo. Considerada de esta manera, la humanitas carece de un contenido positivo desplegable: es una hondura sin fondo que rehúye toda identificación con lo dado.

Habitualmente pensamos en nosotros mismos como en una tercera persona que pudiéramos considerar entre varios (ese que soy yo), y olvidamos que esa tercera persona debe ser atestiguada por alguien que, obviamente, ya no puede ser ese que soy yo. Al olvidar esta obviedad, nos hacemos súbditos del reino de la tercera persona, de los demostrativos, y nos olvidamos de aquello que, siendo lo más próximo, nunca está presente a la mano, nunca está ahí dispuesto para nuestro examen. La educación se convierte, bajo este imperio, en un verterse en moldes de objetividad proporcionados, en su mayor parte, por la tradición, que nos permiten emerger a la superficie de ese dominio anónimo de la tercera persona y adaptarnos a sus quehaceres. Pero si a este momento no le sigue un cierto retorno a sí, un volver en sí saliendo del círculo de la autosugestión, del creerse, no se interioriza realmente lo aprendido, y no se produce la apropiación liberadora de él. Nuestra identificación con ese entramado o complejo de ideas sobre nosotros mismos le presta a éste una conciencia que en realidad no posee. Nos encapsulamos en nuestras creencias y convicciones 
acerca de nosotros mismos y las animamos desde dentro, de suerte que ese reflejo espectral en nuestro mundo privado termina reemplazándonos. La formación humanista o humanizante es la actitud y la disciplina que nos mantiene alerta frente al letargo del andar distraídos confundiéndonos con algo visible o pensable, desvelando esa impostura.

En el presente artículo vamos a adentrarnos en este momento reductivo que consideramos esencial para la formación humanista de la mano sobre todo de Martin Heidegger, pero previamente allanaremos el camino hacia la comprensión de su peculiar Destruktion exponiendo brevemente dos antecedentes que pueden ayudarnos a aclarar su significado, y que encontramos en la idea de formación (Bildung) de Hegel y en la Transzendentale Reduktion de Husserl. En estos tres autores nos encontramos con un humanismo no antropológico en el que lo humano no es lo meramente humano. Los tres autores concuerdan en sostener que lo peculiarmente humano consiste en distanciarse o separarse de todo lo dado, puesto que la barbarie, la alienación que encubre lo humano es precisamente la identificación con algo dado. Mostrar esta coincidencia, a pesar de las divergencias en la caracterización precisa que cada uno de estos grandes filósofos hace de dicha separatio (separatio que, paradójicamente, elimina toda exterioridad), es el principal objeto del presente estudio.

La destrucción heideggeriana no equivale a un arrasar sino a un deshacer lo que encubre. Heidegger emplea el término en este sentido hablando de la tradición histórica pero, ¿acaso no existe una tradición comparable en el interior de cada uno? Estamos a merced, no sólo de la tradición histórica, que sustrae lo que presuntamente transmite ${ }^{4}$, sino también de esa otra traditio interna que exige igualmente ser repensada y acotada dentro de sus límites desde una instancia más originaria, anterior a su constitución. Sólo desde aquí, es decir, abandonándola a contrario sensu, es posible que nos apropiemos de ella y la mantengamos en su sentido verdaderamente humano.

Como señala Lukács, la renuncia es el momento clave en el proceso de formación, en el acceso a la madurez ${ }^{5}$. Esta renuncia se relaciona con la noción de desistir o anonadarse (según traduzcamos "nichten") de Heidegger, y con la reducción al ego puro de Husserl. Y, por supuesto, esta misma mediación de lo negativo considerada como distanciamiento de lo particular e inmediato es la pieza clave en la formación tal como la entiende Hegel. A través de estos autores veremos cómo la humanitas es

4. Cfr. Heidegger, M.: Sein und Zeit. Frankfurt am Main: Vittorio Klostermann, 1977, § 6. En adelante nos referiremos a esta colección de obras de Heidegger, Gesamtausgabe, con las abreviaturas " $G A$ " seguidas del número de volumen correspondiente.

5. Lukács, G.: La théorie du roman. París: Gonthier, 1963, p. 136.

Thémata. Revista de Filosofía №54 (2016) pp.: 281-302. 
fundamentalmente separación, y equivale a un volver en sí que disipa falsas identidades manteniendo la distancia respecto a todo objeto.

Esta separación puede compararse en cierto modo a la que mantiene el intérprete respecto a su personaje. Si nos ha tocado representar un papel, hagámoslo lo mejor posible, como decía Epicteto, pero para hacerlo debemos recordar que, en nuestro ser íntimo, somos el que se oculta tras la máscara. De esta forma, al ceñirnos conscientemente a nuestro papel, éste ya no es ninguna barrera para nosotros sino un cauce de participación. La experiencia del mundo como obra teatral en la que se participa no devalúa en absoluto la tarea humana sino que, por el contrario, la eleva a la categoría de ritual, de actividad que no busca esta o aquella finalidad particular de un individuo sino la culminación de la obra. El actor cobija a ese que ha nacido en su lugar, a su character, a su historia y, en definitiva, a toda la obra, convirtiéndose él mismo en entorno favorable. Se aparta como centro de iniciativas, como sujeto de decisiones para convertirse en medium que se hace transitable, franco, sin inmiscuirse ni oponer resistencia, hasta el punto de disolver toda alteridad respecto al personaje. Para el actor no hay nada exterior, como sí lo hay, en cambio, para el personaje. Así, la separación propia del actor redunda en la eliminación de toda exterioridad.

Por el contrario, no distanciarse e identificarse con el personaje es enajenación, es ruido y furia, como dice Macbeth. La barbarie siempre nos arrastra en la corriente de vivencias enturbiando esa claridad, obturando esa separación sin la cual nos reducimos a personajes que, una vez echado el telón, se esfuman como si nunca hubieran existido. La actitud emancipada, adulta, humanista, es por lo tanto la de distanciarse de todo punto de vista interno al drama.

Esta manera de considerar el humanismo sortea las dificultades planteadas por Heidegger en su célebre Carta sobre el Humanismo ${ }^{6}$. Allí, Heidegger muestra sus recelos ante la idea de recuperar un humanismo que parece condenarnos a asumir una concepción previa metafísica de lo humano, como un ente que ocupa el lugar correspondiente al animal racional en la taxonomía ontológica: "La humanitas del homo humanus se determina desde la perspectiva previamente establecida de una interpretación de la naturaleza, la historia, el mundo y el fundamento del mundo, esto es, de lo ente en su totalidad ${ }^{7}$.

No obstante, según Heidegger, la constatación de este mismo carácter problemático del humanismo puede conducirnos a pensar de modo

6. Encontramos una luminosa meditación del contenido de esta Carta en Choza, J.: "Lectura de la Carta sobre el Humanismo de Heidegger" en Thémata. Revista de Filosofía 32, 2004, pp. 37-82.

7. Heidegger, M.: Carta sobre el Humanismo. Madrid: Alanza Editorial (2a ed.), 2013, p. 27 (GA 9, p. 321).

Thémata. Revista de Filosofía No54 (2016) pp.: 281-302. 
más radical la esencia del hombre ${ }^{8}$ y a situar la humanidad a su altura ${ }^{9}$, no entendiéndola ya como género o especie sino más bien como modo en el que se ejerce una dignidad o título ${ }^{10}$.

Los humanismos históricos son contradictorios en la medida en que generan escuelas o doctrinas, es decir, en la medida en que son ismos ${ }^{11}$. Pero si entendemos la formación humanizante como la revelación de la barbarie de la exterioridad, de la alienación que supone la identificación con el ser de la superficie, no necesitamos ninguna noción metafísica previa de lo humano, ni creamos ninguna doctrina que pueda ser seguida o trasmitida. La humanitas será lo formado en esa askesis humanizante, es decir, la propia hondura.

Esta es la línea que sugiere Heidegger para un posible nuevo humanismo en su Carta: un humanismo que no es ya un ismo al que uno pueda adscribirse porque no ofrece una idea positiva de lo humano a la que podamos asignar una posición en el espacio omniabarcante de lo ente en su totalidad. Lo humano no es explicable desde lo ente, trasciende lo ente. El nuevo concepto de humanismo al que nos conduce Heidegger no es tanto un humanismo basado en lo que sea el hombre, en aquello en lo que estribe su índole propia en comparación con otros entes, sino en su referencia al ser, en su extático habitar en la vecindad del ser, es decir en la ex-sistencia del homo humanus, como veremos en el cuarto y último epígrafe de este estudio.

\section{El concepto de Bildung en Hegel}

Dentro de la tradición del humanismo alemán, el «más grande pensamiento» según Gadamer es el de Bildung ${ }^{12}$. La prehistoria del concepto de Bildung se encuentra en la mística renana tardomedieval cuya figura central es el Meister Eckhart. En este contexto, Bild, la imagen o forma, se entiende en el sentido de la imago dei cristiana $^{13}$, y su producción en el

8. Cfr. GA 9, p. 345.

9. Cfr. GA 9, p. 330.

10. Cfr. Duque, F.: En torno al humanismo. Heidegger, Gadamer, Sloterdijk. Madrid: Tecnos, 2002 , pp. 69 y ss.

11. Precisamente por ello no tiene mucho sentido proponer humanismos de nuevo cuño adaptados a los tiempos actuales o a la democracia por venir. Sobre estos humanismos de nuevo cuño vid. Hoyos Vásquez, G. (Ed.): Filosofía de la educación. Madrid: Editorial Trotta, 2008, pp.13-25.

12. Gadamer, H.-G.: Verdad y método. Fundamentos de una hermenéutica filosófica. Salamanca: Sígueme, 1977, p. 37.

13. Horlacher, R.: Bildung. La formación. Barcelona: Octaedro, 2015, p. 19; Fabre, M.: "Experiencia y formación: La bildung" en Revista Educación y Pedagogía 23/59, 2011, p. 216.

Thémata. Revista de Filosofía $\mathrm{N}^{\circ} 54$ (2016) pp.: 281-302. 
hombre se puede entender como un sacar a la luz lo que se esconde en su oculta interioridad:

Cuando un maestro hace una imagen de madera o de piedra no hace que la imagen entre en la madera, sino que va sacando las astillas que tenían escondida y encubierta a la imagen; no le da nada a la madera sino que le quita y expurga la cobertura y le saca el moho, y entonces resplandece lo que yacía escondido por debajo ${ }^{14}$.

Aquí ya tenemos este carácter reductivo del que venimos hablando y que es la clave de ese dar forma interior. La Bildung no consiste en adquirir una forma por parte de lo carente de ella sino de expurgar toda forma cortical que encubra el centro o corazón humano que es imago dei, es decir, la humanitas que trasciende lo meramente humano. Este momento reductivo de la formación en la tradición humanista alemana lo podemos observar desde sus inicios y se reafirma expresamente en la pedagogía de Hegel.

El movimiento humanista alemán del clasicismo que alcanza su plenitud en el romanticismo de comienzos del siglo XIX es una vuelta a la paideia griega, pero sobre todo es una vuelta al corazón humano. En este movimiento tuvo una gran influencia el pietismo, sobre todo a través del Messias de Klopstock y de los escritos del predicador Friedrich Christoph Oetinger. El pietismo persigue una interiorización de la religión, una religiosidad íntima basada en el autoexamen y la formación interior, que encuentra su espacio, su medio, en el corazón más que en la razón. Oetinger interpreta el concepto de sensus communis de Shaftesbury como percepción de la unidad de todo lo vivo en una única vida compartida, y el centro de este ciclo de vida está en el corazón del hombre, que es por lo tanto desde donde únicamente puede percibirse dicha unidad: la sede del sensus communis ${ }^{15}$. Influido por la lectura de Jacob Böhme, Oetinger considera lo creado como envuelto en un proceso divino, de modo que es la propia actuación del Espíritu del Creador la que hace posible esta cognitio centralis en el corazón de lo creado que está en el hombre ${ }^{16}$.

Pero esa sabiduría del corazón, que es su hospitalidad, se ciega por la actitud de quien, no tomando distancia respecto a sus puntos de vista particulares y a sus motivaciones privadas, se hace incapaz de acoger a lo otro, a lo extraño. La purificación de los motivos egoístas requiere de autoexamen porque el autoexamen supone distancia frente a uno mismo

14. Meister Eckhart: Werke II. Frankfurt am Main: Deutscher Klassiker Verlag, 1993, p. 223. En De la teología mística del Pseudo Dionisio encontramos un pasaje casi idéntico. Vid. Pseudo Dionisio Areopagita: Obras Completas del Pseudo Dionisio Areopagita. Madrid: B.A.C., 1995 , p. 372

15. Cfr. Gadamer, H.-G.: op. cit., pp. 57 y ss.

16. Cfr. Lindberg, C. (Ed.): The pietist theologians: An introduction to theology in the Seventeeth and Eighteeth Centuries. Malden, MA: Blackwell Publishihng, 2005. pp. 242 y ss.

Thémata. Revista de Filosofía №54 (2016) pp.: 281-302. 
y, en esa medida, generalidad. Este proceso de purificación por el autoexamen es Bildung. Según Gadamer, para Hegel es una característica general de la Bildung:

Mantenerse abierto hacia lo otro, hacia puntos de vista distintos y más generales. La formación comprende un sentido general de la mesura y de la distancia respecto a sí mismo, y en esta misma medida un elevarse por encima de sí mismo hacia la generalidad. Verse a sí mismo y ver los propios objetivos privados con distancia quiere decir verlos como los ven los demás ${ }^{17}$.

Pero la adquisición del nuevo punto de vista más general no es lo importante en este proceso: lo crucial es el retorno a sí y la apropiación que supone la apertura del anteriormente logrado, convertido ahora en medio formativo. En este proceso, los logros sólo lo son si se convierten en medios para nuevos logros. No se trata, por tanto, de dar cabida, dentro de sí, a la mayor cantidad de humanidad posible, como afirma uno de los teóricos de la Bildung, Von Humboldt, sino más bien en no dejar de dar cabida, en seguir haciendo sitio. El espíritu vuelve sobre sí interiorizando sus experiencias en un proceso no acumulativo sino creciente, es decir, esa interiorización no es un embotarse sino un separarse que abre espacios dentro. Y esta es la tarea propiamente humana.

Toda la vida es Bildung, formación humana. Esta idea está en el nacimiento del género conocido como novela de formación (Bildungsroman). Hegel, siguiendo una tradición ya consolidada con Herder, trata de comprender toda la historia de la humanidad, la historia de los pueblos, como una especie de novela de formación filogenética en su Fenomenología del Espíritu ${ }^{18}$. Pero también entiende el proceso formativo individual del mismo modo, como el tránsito desde una subjetividad individual marcada por los intereses, miedos y deseos típicos de un ejemplar de la especie humana, del hombre en estado de naturaleza, a lo universal y objetivo. Este tránsito establece la correspondencia entre el ser y el deber ser, puesto que el hombre no es por naturaleza lo que debería ser ${ }^{19}$.

Lo humano se inscribe dentro de la historia de la formación de la conciencia absoluta. Pero lo que para la conciencia absoluta es reencontrase tras su extrañamiento, para la conciencia humana limitada es un calvario $^{20}$. El hombre debe negarse a sí mismo en su individualidad y en su

17. Gadamer, H.-G.: op. cit., p. 46.

18. Cfr. Vilanou, C.: "Formación, cultura y hermenéutica: De Hegel a Gadamer" en Revista de Educación 328, 2002, p. 208.

19. Cfr. Santos Herceg, J.: "Amor, vida, formación: Tras la huella del Espíritu Hegeliano" en Thémata. Revista de Filosofía 24, 2002, p. 239.

20. Para profundizar en este enfoque de la filosofía hegeliana vid. Polo, L.: El yo. Pamplona: Servicio de Publicaciones de la Universidad de Navarra, 2004, pp. 73 y ss.

Thémata. Revista de Filosofía №54 (2016) pp.: 281-302. 
ser natural, que es algo que consuma pacientemente, subordinando la particularidad con la que está familiarizado y con la que se identifica a la generalidad de la conciencia, que le resulta ajena, a través de la disciplina y el trabajo que se impone el propio espíritu para elevarse de su inmediatez.

El hombre sin formación se identifica con algo particular y permanece en la intuición inmediata, por lo que no ve las cosas como son esencialmente sino desde su punto de vista unilateral, subjetivo, y trata de aprovecharse de ellas siguiendo sus intereses individuales. La formación supone el abandono de esta actitud para mantener a «lo objetivo en su libertad $\rangle^{21}$, para respetarlo. Un paso para ello es elevarse al interés general de una comunidad. Lo vano es, en cambio, lo mantenido exclusivamente por el sujeto: lo puramente subjetivo.

En Hegel, la formación es una interiorización de lo aprendido que se realiza de un modo parecido a como nos apropiamos de algo por la memoria (Erinnerung), es decir, como algo que somos nosotros mismos. En nuestros recuerdos buceamos: carecen de la exterioridad impenetrable y resbaladiza de las cosas. Ello supone una radical transformación de lo aprendido que va unida a una profundización liberadora en la experiencia de sí. El hombre debe convertir todo lo dado, lo inmediato:

En algo suyo, de forma que lo despoje de la forma de la existencia externa (...) Es algo así como un elemento o material que él debe elaborar en todas las direcciones para que el mismo no tenga en sí nada extraño, quebradizo o resistente. En la medida en que lo he convertido completamente en lo mío, para mí, soy libre en ello².

Todo esto, no obstante, requiere del trabajo de lo negativo, de no quedarse en ninguna identificación parcial fruto de la reflexión. Si me detengo en algún momento del proceso, tal momento ya no es mío y no soy libre en él, sino que me enclaustro en él, desatendiendo mi formación y traicionando al Espíritu. Toda detención es hinchazón, infatuación.

Para reconocerse en lo extraño es preciso tomar distancia, sin cesar, de sí mismo ${ }^{23}$. Sólo así es posible elevarse a la universalidad de la conciencia que en cada momento aparece como algo ajeno. La formación

21. Hegel, G. W. F.: "Rechts, Pflichten und Religionslehre für die Unterklasse" en Hegel, G. W. F.: Nürnberger Schriften. Leipzig: F. Meiner, 1938, § 42. Disponemos de este texto en línea en Georg Wilhelm Friedrich Hegel Nürnberger und Heidelberger Schriften 1808-1817, http://hegel.nuernberger-heidelberger.schriften.phil-splitter.com/ [consultado: 22/11/2015]. Traducción: Hegel, G. W. F.: Escritos pedagógicos. México D.F.: Fondo de Cultura Económica, 1991, p. 185.

22. Hegel, G. W. F.: Escritos cit., p. 187 ("Rechts" cit., § 44). Hemos alterado la traducción del término "Dasein" que ofrece el traductor, Arsenio Ginzo, en este fragmento. En lugar de "ser-ahî" hemos escrito "existencia", para que no haya confusión con el sentido heideggeriano del mismo término.

23. Cfr. Hegel, G. W. F.: "Rechts" cit., § 42.

Thémata. Revista de Filosofía No54 (2016) pp.: 281-302. 
supone un mantener la mirada "por encima de sí» ${ }^{24}$. A esto lo llama Hegel "circunspección" (Besonnenheit). La circunspección es un encontrase con el espíritu en medio de las ocupaciones, en el goce o en el trabajo, en cualquier estado singular, en la medida en que uno no se sumerge completamente en él y se encuentra consigo fuera del mismo.

La formación hegeliana es una anamnesis entendida, no como un recordar esto o aquello sino como un recordar-se, un reencontrase o volver en sí que guarda el botín obtenido durante este trayecto, que es una especie de rodeo que parte del Sí mismo (Sich) y conduce al Sí mismo. Pero no es un recordarse o volver en sí del hombre sino a través del hombre. Es un proceso que traspasa lo humano que, en cada momento de ese proceso, sigue siendo finitud. Lo humano no es el Sí mismo, que está siempre a la espalda del yo, sino el proceso mismo del retorno, así que el momento de lo humano no es el de la identidad final sino el de la desidentificación que media. Para el hombre, toda identificación es precipitada (y en Hegel la falsedad es eso, precipitación).

Por su parte, el botín obtenido es protéico: las experiencias acumuladas se convierten en propiedad, se interiorizan, sólo al final del trayecto, y es por eso que cada nuevo nivel alcanzado en el proceso formativo supone una reformulación de todos los anteriores, un formar lo formado, de modo que lo humano no es lo definitivo, que sólo se da en un final que lo subsume, sino la negatividad en acción que media en el proceso.

Sin embargo, Heidegger considera que en Hegel no hay realmente negatividad porque Hegel no acaba de tomarse en serio el no y el anonadar (nichten). En Hegel, la negatividad, el anonadamiento, es un salto al vacío pero con red debajo. Al situarse Hegel en el final, en el punto de vista del Saber Absoluto, subsume la negación en la afirmación ${ }^{25}$, y esto hace que la negatividad no sea sincera, que no sea algo serio sino una especie de dramatización.

En cualquier caso, el Saber Absoluto no es lo humano. La evidencia de la negatividad es la evidencia de la relación entre hombre y ser, pero mientras Hegel piensa esta relación en términos dialécticos, Heidegger lo hace en términos de libertad trascendental: para el Dasein la historia del ser está siempre por venir. El hombre toma ventaja (voraus-habe) sobre todo lo ya llegado a ser. La existencia del hombre no consiste en ser sí mismo ni está determinada por ello ${ }^{26}$.

24. Hegel, G. W. F.: Escritos cit., p. 186 ("Rechts" cit., § 43).

25. Cfr. Heidegger, M.: Hegel. Buenos Aires: Biblioteca Internacional Martin Heidegger, 2005, p. 101.

26. Cfr., GA 9, p. 375.

Thémata. Revista de Filosofía $\mathrm{N}^{\circ} 54$ (2016) pp.: 281-302. 


\section{La reducción al ego puro en Husserl}

En la fenomenología de Husserl nos volvemos a encontrar con la necesidad de un distanciamiento que destruya toda exterioridad (Aussereinander) para alcanzar la verdadera profundidad humana. El homo humanus en este caso es denominado "funcionario de la humanidad", en tanto que consuma la mayor transformación (semejante a una conversión religiosa) a la que puede optar esa humanidad ${ }^{27}$. Dicha transformación supone cierta deshumanización (Entmenschlichung) en la media en que el hombre deja de reconocerse como una parcela del mundo con una naturaleza o índole propia frente a otras.

Según Husserl, el hombre se ha olvidado de sí, se ha perdido en el mundo positivo, que es el mundo común a la actitud ingenua natural y a la científica. De acuerdo con esa actitud, el mundo es algo previamente dado y dotado de una existencia exterior que se supone y que nos ofrece posibilidades de exploración y manipulación. Para volver a reencontrase, el hombre debe abandonar ese mundo, es decir, esa actitud natural, dar un paso atrás, y recuperar el mundo como meditación universal sobre sí mismo: "Nolis foras ire, dice San Agustín, in te redi, in interiore homine habitat veritas ${ }^{28}$. Tras el cambio de actitud, el mundo aparece como tema en la meditación en torno al imperativo délfico "conócete a ti mismo". Tras el derrocamiento del mundo como un ahi afuera nos adentramos en la experiencia egológica (egologishe Erfahrung), es decir, salir del mundo disipa su exterioridad.

Para Husserl, el mundo de la vida (Lebenswelt), sólo se recupera mediante la reducción transcendental, es decir, abandonando el ser de la superficie, y sumergiéndose en la espiritualidad viviente del mundo que es la consciencia trascendental. No obstante, existe un peculiar antagonismo entre introducirse en esa dimensión de espiritualidad viviente (lebendigen Geistigkeit $)^{29}$ y los intereses de la vida mundana.

La reducción trascendental y la epojé que la lleva a cabo suponen un liberarse, un estar por encima, de la dación previa del mundo, de modo que «con y en esta liberación está dado el descubrimiento de la correlación universal (...) entre el mismo mundo y la conciencia del mundo» ${ }^{30}$. La reducción supone un distanciarse de la experiencia ingenua que ahonda en la

27. Cfr. Husserl, E.: Die Krisis der europäischen Wissenschaften und die Transzendentale Phänomenologie. Eine Einleitung in die Phänomenologische Philosophie. La Haya: Martinus Nijhoff, 1976, p. 140; 159 (en adelante nos referiremos a esta colección de obras de Husserl, Husserliana, como HUA).

28. Husserl, E.: Meditaciones cartesianas. Madrid: Tecnos, 2009, p. 2004 (HUA I, p. 183).

29. Cfr. HUA VI, p. 121.

30. Husserl, E.: La Crisis de las Ciencia Europeas y la fenomenología transcendental. Barcelona: Crítica, 1991, p. 159 (HUA VI, p. 154).

Thémata. Revista de Filosofía No54 (2016) pp.: 281-302. 
subjetividad hasta reconocerse conciencia trascendental. De esta manera, el yo, en tanto que se descubre conciencia trascendental, queda purificado de todo comercio con lo objetivo. La libre epojé revela al yo puro: «ese yo y la vida del yo que me queda (...) no es un trozo de mundo, y decir, "Yo soy, ego cogito" no significa ya: "Yo, ese hombre, soy" ${ }^{31}$. Gracias al salto de la epojé «me capto puramente como yo» ${ }^{32}$, me gano a mí mismo como ego puro: "ya no soy yo el que se encuentra como hombre en la experiencia natural de sí mismo»" ${ }^{33}$, en su lugar, obtengo "el reino de la experiencia fenomenológica-trascendental de mí mismo» ${ }^{34}$. Este es el paradójico humanismo deshumanizante del que hablamos: ya no puedo decir "yo, ese hombre, soy". El yo puro "está perfectamente vacío de componentes esenciales, no tiene absolutamente ningún contenido desplegable, es en sí y por sí indescriptible: yo puro y nada más» ${ }^{35}$.

Por lo tanto, en Husserl, la barbarie de la que esta nueva meditación humanista debe liberar al hombre refrendando su humanitas es la actitud ingenua, ya sea natural o científica, que lo considera como una parcela del mundo, es decir, la barbarie es la identificación con un yo empírico, con un yo objetivo. Lo esencial en el ser humano es hacer posible todo objeto sin ser él mismo objeto: el yo reducido o puro es por lo tanto la subjetividad para la cual todo lo demás es objeto; es, por lo tanto, el yo último y absoluto.

El yo se constituye como un yo desarrollado (entwickelten) en cascada, en el sentido de que los sedimentos de sus experiencias (Habitualitäten) se comportan como elementos co-constituyentes (co-conscientes) en los siguientes niveles de constitución ${ }^{36}$. Pero la tarea pura y auténticamente humana ${ }^{37}$ es la experiencia trascendental de volver atrás abandonando la actitud natural por la del espectador desinteresado (uninteressierter Zus(chauer) ${ }^{38}$, que no es simplemente otra actitud, sino un volver a la posición previa que se esconde en la natural o ingenua y la hace posible en la me-

31. Husserl, E.: Meditaciones cit., p. 35. (HUA I, p. 64).

32. Ibídem, p. 29 (HUA I, p. 60).

33. Ibídem, p. 35 (HUA I, p. 64).

34. Ibidem, p. 36 (HUA I, p. 65).

35. Husserl, E.: Ideas relativas a una fenomenología pura y una filosofía fenomenológica. México, D. F.: Fondo de Cultura Económica, 1973, p. 190 (HUA III/I, p. 179).

36. Para entender el concepto de pasividad en la fenomenología genética vid. Osswald, A. M.: "El concepto de pasividad en Edmund Husserl" en Areté. Revista de Filosofía 26/1, 2014, pp. 33-51.

37. Sola Diaz, $\mathrm{M}^{\mathrm{a}}$ del A.: La idea de lo trascendental en Heidegger. Sevilla: Editorial Kronos, 2002, p. 24.

38. Cfr. HUA I, p. 73.

Thémata. Revista de Filosofía ํ54 (2016) pp.: 281-302. 
dida en que es el espacio original de sentido del que deriva todo posible sentido (incluido, el de un mundo exterior).

No obstante, Husserl no abandona la inmanencia de la subjetividad (eso le parecería misticismo), no rompe su fondo yendo fuera del sujeto, como reza el título de la obra de su alumno, Lévinas, y su fenomenología se encamina hacia una monadología ${ }^{39}$. El proceso de formación humanizante o Bildung, ese expurgar o reducir todo lo cortical del que hablaba el Meister Eckhart, se detiene, en el caso de Husserl, en la conciencia que Husserl llama "trascendental" porque la considera el principio constituyente último, no de las realidades, sino de los sentidos (entre ellos el propio sentido de realidad). El yo puro, que identifica con esa conciencia, es una suerte de sujeto cuyos predicados o atributos se despliegan desde sí en la medida en que avanza la experiencia. Esta experiencia, cualquiera que sea, es experiencia trascendental de sí mismo, y redunda en el desarrollo de un yo constituido finito.

En nuestra opinión, la conciencia trascendental de Husserl es el conocimiento no objetivo sino habitual de la pura antecedencia mental. Por ello es lo absolutamente apodíctico: su misma negación, como debe darse de algún modo en la conciencia, la demuestra. Si el sujeto es eso, la única manera de profundizar en su conocimiento es en el modo de un despliegue, es decir, entendiendo el sujeto como un principio constituyente que se reconoce a la vez que se desarrolla en dicho despliegue. Las afinidades con Leibniz son obvias. Esa solución problematiza la intersubjetividad (como advirtió Husserl) y además encierra una paradoja, pues el sujeto no se reconoce en su pureza desplegándose, sino que más bien dicho desarrollo encubre su pureza, su distinguirse de todo objeto.

De modo que hay dos momentos en el proceso de autoconocimiento, un momento constituyente y otro reductivo que recuerdan a Hegel en la medida en que el momento constituyente es llevado a cabo por la conciencia trascendental mientras que el momento reductivo debe ser soportado por la conciencia finita, por el yo limitado o desarrollado, el yo humano: este hombre que soy yo, por utilizar la expresión de Husserl, debe dejar de ser ese hombre que soy yo para reconocerse conciencia trascendental, debe dar un paso atrás y renunciar a toda identificación apartándose de la corriente de vivencias. Éste es el momento verdaderamente humanizante que, como ya dijimos, es en cierto modo deshumanizante. Lo humano trasciende lo humano renunciando a esa parcela del mundo que es el yo

39. Vid. Iribarne, J. V.: La fenomenología como monadología. Buenos Aires: Academia Nacional de Ciencias/Centro de Estudios Filosóficos, 2002.

Thémata. Revista de Filosofía №54 (2016) pp.: 281-302. 
empírico, pero no puede abandonar la inmanencia de la conciencia con el aislamiento que ello comporta.

En Husserl puede adivinarse una tensión entre motivaciones divergentes: por una parte le mueve el espíritu cartesiano que busca sentar las bases de una ciencia primera absuelta de todo presupuesto y, en este sentido, Husserl es un filósofo que se atiene al criterio de certeza, pero, por otra, pretende superar el positivismo y el cientificismo que dominan el panorama cultural de su época y que han convertido al ser humano en una parte del mundo volviendo a un humanismo que ahonde en el carácter trascendental del hombre. Pero para ahondar en ese carácter y no reducirlo a la pura antecedencia mental es preciso superar el criterio de certeza, algo que, como decimos, sería pura irracionalidad para Husserl.

Heidegger se adentrará por sendas que trascienden esa subjetividad tan característica de la filosofía moderna. Para él, la libertad propia del dasein humano no es la de un principio constituyente. Su noción de trascendencia, como veremos a continuación, es distinta de la de Kant o Husserl, ya que no es aquello que aporta a priori las condiciones de sentido respecto a cualquier experiencia. Lo trascendental en Heidegger es lo que trasciende, lo que lleva a cabo el trascender como indigencia de fundamento, como abismo.

\section{El anonadamiento (Nichtung) en Martin Heidegger}

En la obra de Heidegger, esa barbarie que falsea la esencia de lo humano es caracterizada como olvido del ser u olvido de la diferencia ontológica entre el ser y el ente. El olvido del ser no sólo afecta a la historia de la filosofía o de la metafísica, sino que es un estado de la existencia humana que determina el modo en el que el hombre está en el mundo ${ }^{40}$. El olvido del ser deja escapar todo lo saludable (heilsame) del ente ${ }^{41}$. Este estado enfermizo, sin embargo, forma parte del destino de la verdad del ser. El olvido lo es del elemento en el que se mueve lo humano, el que lo capacita alimentándolo y otorgándole un sentido.

Lo humano se encuentra, de entrada, embarcado en una misión (el proyecto extático) a la que ha sido destinado o arrojado ${ }^{42}$. Pero el olvido de este destino y la recuperación de su memoria, no es un lapsus del destino,

40. Cfr. Cavallé, M.: La sabiduría de la no-dualidad. Una reflexión comparada entre Nisargadatta y Heidegger. Barcelona: Kairós, 2000, p. 239.

41. Cfr. GA 6.2, p. 357.

42. «Ex-sistiendo, el hombre se encuentra ya en el destino del ser». Heidegger, M.: Carta cit., p. $52(G A 9$, p. 336).

Thémata. Revista de Filosofía N54 (2016) pp.: 281-302. 
sino quizá su episodio crucial. La recuperación de este proyecto extático ocupa el lugar de la Bildung hegeliana.

En Qué es metafísica (1929), una obra de la etapa de Ser y tiempo, nos encontramos con esta rotunda afirmación: «ser-aquí [da-sein] significa estar inmerso en la nada» ${ }^{43}$. De este modo, «estando inmerso en la nada, el Dasein está siempre más allá de lo ente en su totalidad. Este estar más allá de lo ente es lo que llamamos trascendencia» ${ }^{44}$. El elemento, por tanto, en el que se mueve lo humano está más allá de lo ente: el hombre es «lugarteniente de la nada ${ }^{45}$.

Sin embargo, esta nada, esta originaria trascendencia, se nos disimula en la medida en que de modo habitual nos perdemos en lo ente. En la medida en que nuestro quehacer es lo ente, damos la espalda a esa trascendencia y nos precipitamos a la superficie del Dasein $n^{46}$. Pero esto es lo propio de esa nada, de esa trascendencia: su desistir nos remite al ente y hace posible su manifestación ${ }^{47}$. Al desistir, rechazando a lo ente en su totalidad, remite a él y «lo revela como aquello absolutamente otro a la nada» ${ }^{48}$. De ahí la originaria extrañeza que provoca el encuentro con el ente. El Dasein «está completamente atravesado por una conducta que consiste en desistir» ${ }^{49}$.

En este punto nos acordamos de aquello que escribe el Pseudo Dionisio en la Carta I al Monje Gayo: «la luz hace invisible la tiniebla». Existe una tiniebla originaria que hace posible la aparición de todo objeto, un silencio que hace posible todo decir ${ }^{50}$, pero a costa de ser encubierto.

El camino de regreso que devuelve lo humano a su elemento es pensar el ser. Pensar el ser es un pensar originario anterior a cualquier pensar teórico o práctico, un pensar que no proporciona resultados, que no supone ninguna ventaja competitiva, pero que afecta profundamente a la libertad del hombre. No es un pensar episódico, no es una acción humana. Más bien, pensar el ser es estar llevando a cabo la diferencia ontológica, y este llevar a cabo esta diferencia es la humanitas del hombre: aquello que lo distingue ${ }^{51}$. La ontología es, antes que nada, el propio hombre, así que

43. Heidegger, M.: Qué es metafísica. Madrid: Alianza Editorial (2ª ed.), 2014, p. 35 (GA 9, p. 115).

44. Idem.

45. Ibidem, p. 40 (GA 9, p. 118).

46. Cfr. GA 9, p. 116.

47. Cfr. GA 9, p. $115 ; 116$.

48. Heidegger, M.: Qué es Metafísica cit., p. 34 (GA 9, p. 114).

49. Ibídem, p. 39 (GA 9, p. 117).

50. Sobre la elocuencia del silencio en Heidegger vid. Muñoz Martínez, R.: Tratamiento ontológico del silencio en Heidegger. Sevilla: Fénix Editora, 2006.

51. Cfr. GA 24, p. 454.

Thémata. Revista de Filosofía №54 (2016) pp.: 281-302. 
la ontología como tratado llega tarde, y se convierte en sello erudito de esa evidencia (que el hombre no es óntico sino ontológico). De este modo, el pensar debe dar un paso atrás (Schritt zurück), debe ser un tipo de pensar que rememora (Andenken).

La diferencia entre ser y ente no es una relación (un ens minimum) entre entes. Esta diferencia es llevada a cabo por el Dasein como su existir. ¿Cómo entender esto?: como ahondamiento. El ahondamiento mantiene la distancia con lo ya llegado que encubre, es decir, con lo ente, se abisma rehusando todo fundamento y protección en lo ente (Ab-grund) y, de esta forma, se mantiene abierto al sobrevenir ${ }^{52}$, lo espera más adentro, más próximo. Ésta es la trascendencia propia del Dasein. El ahondamiento deshace el encubrimiento del ser por el ente: rehúye el ente. Pero, a la vez, crea el entretanto (inzwischen) que abre un espacio-tiempo originario en el que se hace posible la manifestación de lo ente y, por lo tanto, el ocultamiento o recogimiento del ser en lo ente. Es la renuncia del Dasein a todo fundamento en el ente, su trascender o ser extático en orden al ser, lo que revierte en su extático ser-en-el-mundo (In-der-Welt-sein).

Cuando Heidegger dice que el hombre es ser-en-el-mundo y que éste es el rasgo fundamental de su humanitas no debemos entender que el hombre es un ser mundano. "Mundo" en esa expresión no significa un ente, ni mundano ni supramundano, sino la apertura del ser ${ }^{53}$. El hombre ex-siste en esa apertura y desde este ex el mundo aparece como el allá dentro de la ex-sistencia y para ella ${ }^{54}$. Pero este "ex" respecto del mundo es una vertiente de la trascendencia del anonadamiento, del salto al no, del a-bismo. Este punto difícil y crucial lo explica Heidegger, a su manera, en La negatividad. Una confrontación con Hegel desde el planteamiento de la negatividad, que compone entre 1938 y 1941.

Allí nos dice Heidegger que la di-ferencia es separación, un salto en el no, o a ese no del anonadamiento que es el ser $^{55}$. El ser-ahí es la afirmación de la verdad del ser, el sí al anonadamiento y a la necesidad del no, que es el no a la adhesión y consentimiento al ente ${ }^{56}$. De modo que el no, es el sí al anonadamiento, que es el sí al a-bismo, el sí al interrogar a lo más digno de

52. Las relaciones entre llegada (Ankunft) y sobrevenida (Überkommnis) en la filosofía última de Heidegger son tratadas en Sola Díaz, $\mathrm{M}^{\mathrm{a}}$ del A.: op. cit., pp. 64 y ss.

53. Cfr. GA 9, pp. 349-350.

54. Cfr. Ibídem, p. 350.

55. Cfr. Heidegger, M.: Hegel cit., p. 93.

56. Cfr. Ibídem, p. 101

Thémata. Revista de Filosofía N54 (2016) pp.: 281-302. 
ser cuestionado ${ }^{57}$. Este interrogar, sin embargo, no es un sonsacar, porque es silencioso, sino un dignificar a lo más digo de ser cuestionado.

El a-bismo abierto es el entretanto, el claro de lo despejado en el que está (extáticamente) el hombre y que lo determina esencialmente. Esto no es explicable desde lo ente. No es el hombre y, además, el estar. En cuanto ex-sistente, el hombre soporta el ser aquí en la medida en que toma a su cuidado el aquí como claro del $\operatorname{ser}^{58}$. Y este su ser aquí es su ser arrojado o destinado.

La nada, el a-bismo, "es el re-huso del fundamento, de todo apoyo y protección en lo ente» ${ }^{59}$. Este re-huso (de "rehuir", "Ver-sagen") es indigencia de decisión y de diferenciación. El anonadamiento, como re-huso del fundamento, es concesión de la pureza de la indigencia de fundación ${ }^{60}$. Y esta indigencia es "el máximo otorgamiento» ${ }^{61}$.

El a-bismo, la nada, es el ser mismo, «no porque éste [sea] lo más vacío o general, más descolorido, último vaho, sino lo más rico, único, el centro, que no [es] mediado y por eso nunca revocable» ${ }^{62}$.

En la posterior Carta sobre el Humanismo (compuesta en 1946 y publicada en 1947), pensar el ser se nos presenta como la experiencia de habitar o morar (wohnen) en la vecindad del ser, en lo abierto del ser. Lo abierto (Offene) es un motivo que aparece ya en la poesía de Hölderlin (como en Der Gang aufs Land). Lo abierto es el claro (Lichtung), la parcela desbrozada o el cielo despejado. El claro es lo transitable, lo interiormente franco que hace posible el aparecer, el estar presente, como el claro del bosque hace posible el baile de los lugareños. El claro es lo liberado de opacidad, lo abierto a ser atravesado por la luz o a permanecer en tinieblas. Es anterior por lo tanto a toda presencia y a toda ausencia, pero en ese claro abierto y libre es donde se reúne todo como lo des-cubierto o des-ocultado, es decir, como verdad.

Pensar el ser es habitar en su vecindad, es decir, en ese claro. Pero habitar no quiere decir residir sino cuidar. El cuidado no es una acción directa sobre la cosa sino la producción del emplazamiento adecuado, de las condiciones favorables para su desarrollo, para su crecimiento, y la protección frente a las posibles amenazas de un entorno hostil. Habitar cuidando es aviar, disponer espacios, construir en un sentido no tectónico,

57. Cfr. Ibídem, p. 103

58. Cfr. GA 9, p. 327.

59. Heidegger, M: Hegel cit., p. 101.

60. Cfr. Ibídem, p. 99.

61. Ibidem, p. 101.

62. Ibidem, p. 99.

Thémata. Revista de Filosofía №54 (2016) pp.: 281-302. 
no técnico ${ }^{63}$. Cuando Heidegger habla de "dejar ser" no está pensando en una actitud pasiva, sino en una acción que, a pesar de no ser invasiva, tampoco es meramente teórica o contemplativa, sino que es un producir en el sentido de conducir, de llevar adelante. Es amor en acción, crianza.

De esta manera, el hombre es el cuidador o el pastor del ser ${ }^{64}$. Es destinado por el ser y para el ser en orden a su verdad. La esencia del existir humano es ser el ahi de la verdad del ser, su morada y custodia, y a ese morar extático en la proximidad del ser guardando su verdad lo llama Heidegger ex-sistencia ${ }^{65}$. Hay una trascendencia que es constitutiva del modo de existir del hombre. El ser el ahí de la verdad del ser tiene carácter extático: el extático estar dentro de la verdad del ser, y este carácter extático reside en la ex-sistencia.

Relacionando esto último con la separación, con la di-ferencia, Heidegger precisa que hay que entender ese "afuera" ("hinaus") del ex, "como un ir hacia el afuera o lo exterior de la separación que constituye la diferencia (el aquí) y no en el sentido de salir fuera de un interior» ${ }^{66}$. La esencia de ese éxtasis debe ser pensada como un estar fuera como soporte, como el "aquî" del des-ocultamiento: «El estar de lo extático reside, por raro que pueda sonar, en el estar dentro en el "fuera" y en el "aqu'́" $\|^{67}$.

Si el Dasein deja ser a lo ente, no lo hace como un sujeto que renuncia "sino que el ser-aquí desiste en la medida en que por ser la esencia en la que el hombre ex-siste, él mismo pertenece a la esencia del ser» ${ }^{68}$. Esta negatividad no es el «insistir obstinado de la fuerza impositiva de la subjetividad, sino (...) un 'no' de la ex-sistencia que deja ser, [que] está respondiendo a la llamada del desistir surgido en el claro ${ }^{69}$ ”.

Pensar el ser es un pensar más originario, anterior al pensar de un sujeto sobre esto o aquello puesto que es el "entretanto" que hace posible este pensar, hace posible al sujeto y hace posible al esto o al aquello. Es un pensar que permite descender a la proximidad de lo más próximo. Este descenso «conduce a la pobreza de la ex-sistencia del homo humanus. En la ex-sistencia se abandona el ámbito del homo animalis de la metafísica» ${ }^{70}$. La ex-sistencia es la humanitas del hombre, pero ahí lo esencial es el ser

63. Cfr. $G A 7$, pp. 143 y ss.

64. Cfr. GA 9, p. 331.

65. Cfr. Ibidem, p. 326.

66. Heidegger, M.: Carta cit., p. 36 (GA 9, p. 326).

67. Heidegger, M.: Qué es Metafísica cit., p. 8 (GA 9, p. 374).

68. Ibídem, pp. 88-89 (GA 9, p. 360).

69. Ibidem, pp. 86-87 (GA 9, p. 359).

70. Heidegger, M.: Carta cit., p. 76 (GA 9, p. 352).

Thémata. Revista de Filosofía N54 (2016) pp.: 281-302. 
que otorga esa dimensión extática a la ex-sistencia ${ }^{71}$. Humanismo quiere decir: lo más importante es la verdad del ser. El prodigarse del hombre en la verdad del ser, el pensar esencial, es el agradecer originario que responde a la gratuidad con la que el ser ha otorgado al hombre el ser la guarda de su verdad ${ }^{72}$. Esa es la dignidad de la humanitas: el sacrificio u ofrenda que responde o es eco del favor del ser.

Pensar el ser es experimentar la esencia de ese pensar, lo que equivale a llevar a cabo dicha esencia, a dejar que acontezca. Esto es sereno abandono (Gelassenheit). Este pensar es «dejar todo lo nuestro y dejarnos a nosotros mismos: pura espera, acogida de lo que viene, cuando quiera venir» ${ }^{73}$. Como para su maestro Husserl, también para Heidegger la actitud (Haltung) es lo realmente crucial, aunque él amplía el sentido de este concepto. Heidegger entiende la fe o la esperanza como actitud ${ }^{74}$, es decir, la sitúa en un nivel radical, ya que ni la fe ni la esperanza dan razón de sí mismas (no son un "insistir obstinado de la fuerza de la subjetividad"), como tampoco se explica a sí misma esa tarea pura y auténticamente humana que es adentrase en la escucha de aquello a lo que nosotros mismos pertenecemos. Existe una co-pertenencia entre hombre y ser, una suerte de Alianza ${ }^{75}$.

Reconocerse en la "pobreza del pastor, cuya dignidad consiste en ser llamado por el propio ser para la guarda de su verdad» ${ }^{76}$, es reencontrase con nuestra humanitas. Esta es la dignidad de la humanitas que el humanismo auténtico pretende rememorar. Desistir o anonadarse en beneficio de la verdad del ser es el modo del existir humano, su extático morar cobijando el claro de la verdad del ser. Y esto debe ser refrendado de manera no tautológica como experiencia, como historia y vida, puesto que el hombre debe ratificar su humanidad reescribiendo esa verdad. El hombre debe ser humano de modo redundante.

«No sabiendo cuando llegaría la mañana, dejé abiertas todas las puertas», escribió Emily Dickinson, con quien iniciamos este artículo. Quizá, hasta que no sepamos qué sea habitar en la proximidad de nuestro daimon no sabremos tampoco el verdadero significado de "morada" o "morar",

71. Cfr. GA 9, p. 333-334.

72. Cfr. GA 9, pp. 309-310.

73. Rivera, J. E., cit. por Muñoz Martínez, R.: op. cit., p. 36.

74. Sobre la importancia de la actitud en Heidegger vid. Grassi, E.: Heidegger y el problema del humanismo. Barcelona: Anthropos, 2006, pp. 77 y ss.

75. Sobre éste y otros motivos bíblicos reformulados por Heidegger vid. Von Balthasar, H. U.: Gloria. Una estética teológica 5. Metafísica. Edad Moderna. Madrid: Ediciones Encuentro, 1988, pp. 403 y ss.

76. Ibídem, p. 61 (GA 9, p. 342).

Thémata. Revista de Filosofía №54 (2016) pp.: 281-302. 
como dice Heidegger, pero, mientras tanto, dejemos abiertas, como la Loca del Ático, todas las puertas.

\section{Referencias bibliográficas}

Cavallé, M.: La sabiduría de la no-dualidad. Una reflexión comparada entre Nisargadatta y Heidegger. Barcelona: Kairós, 2000.

Choza, J.: "Lectura de la Carta sobre el Humanismo de Heidegger" en Thémata. Revista de Filosofía 32, 2004, pp. 37-82.

Duque, F.: En torno al humanismo. Heidegger, Gadamer, Sloterdijk. Madrid: Tecnos, 2002, pp. 69 y ss.

Fabre, M.: "Experiencia y formación: La Bildung" en Revista Educación y Pedagogía 23/59, 2011, pp. 215-225.

Gadamer, H.-G.: Verdad y método. Fundamentos de una hermenéutica filosófica. Salamanca: Sígueme, 1977.

Grassi, E.: Heidegger y el problema del humanismo. Barcelona: Anthropos, 2006, pp. 77 y ss.

Hegel, G. W. F.: "Rechts, Pflichten und Religionslehre für dieUnterklasse" en Hegel, G. W. F.: Nürnberger Schriften. Leipzig: F. Meiner, 1938.

Heidegger, M.: Die Grundprobleme der Phänomenologie. Frankfurt am Main. Vittorio Klostermann, 1975 (GA 24).

Heidegger, M.: Hegel. Buenos Aires: Biblioteca Internacional Martin Heidegger, 2005.

Heidegger, M.: Sein und Zeit. Frankfurt am Main: Vittorio Klostermann, 1977 (GA 2).

Heidegger, M.: Vorträge und Aufsätze. Frankfurt am Main. Vittorio Klostermann, 2000 (GA 7).

Heidegger, M.: Wegmarken. Frankfurt am Main: Vittorio Klostermann, 1976 (GA 9).

Horlacher, R.: Bildung. La formación. Barcelona: Octaedro, 2015.

Hoyos Vásquez, G. (Ed.): Filosofía de la educación. Madrid: Editorial Trotta, 2008.

Husserl, E.: Cartesianische Meditationen und Pariser Vorträge. La Haya: Martinus Nijhoff, 1973 (HUA I).

Husserl, E.: Die Krisis der europäischen Wissenschaften und die transzendentale Phänomenologie. Eine einleitung in die phänomenologische philosophie. La Haya: Martinus Nijhoff, 1976 (HUA VI).

Husserl, E.: Ideen zu einer reinen Phänomenologie und phänomenologischen Philosophie. La Haya: Martinus Nijhoff, 1977 (HUA III/I).

Iribarne, J. V.: La fenomenología como monadología. Buenos Aires: Academia Nacional de Ciencias/Centro de Estudios Filosóficos, 2002. 
Johnson, T. H. (Ed.): The Complete Poems of Emily Dickinson. Londres: Faber and Faber, 1970.

Lindberg, C. (Ed.): The pietist theologians: An introduction to theology in the Seventeeth and Eighteeth Centuries. Malden, MA: Blackwell Publishihng, 2005.

Lukács, G.: La théorie du roman. París: Gonthier, 1963.

Meister Eckhart: Werke II. Frankfurt am Main: Deutscher Klassiker Verlag, 1993.

Mulder, W.: "Seeing New Englandly: Planes of Perception in Emily Dickinson and Robert Frost" en The New England Quarterly 52/4, 1979, pp. 550-559.

Muñoz Martínez, R.: Tratamiento ontológico del silencio en Heidegger. Sevilla: Fénix Editora, 2006.

Osswald, A. M.: "El concepto de pasividad en Edmund Husserl" en Areté. Revista de Filosofía 26/1, 2014, pp. 33-51.

Polo, L.: El yo. Pamplona: Servicio de Publicaciones de la Universidad de Navarra, 2004.

Pseudo Dionisio Areopagita: Obras Completas del Pseudo Dionisio Areopagita. Madrid: B.A.C., 1995.

Santos Herceg, J.: "Amor, vida, formación: Tras la huella del Espíritu Hegeliano" en Thémata. Revista de Filosofía 24, 2002, pp. 227-243.

Sola Diaz, $\mathrm{M}^{\mathrm{a}}$ del A.: La idea de lo trascendental en Heidegger. Sevilla: Editorial Kronos, 2002.

Vilanou, C.: "Formación, cultura y hermenéutica: De Hegel a Gadamer" en Revista de Educación 328, 2002, pp. 205-223.

Von Balthasar, H. U.: Gloria. Una estética teológica 5. Metafísica. Edad Moderna. Madrid: Ediciones Encuentro, 1988. 


\section{RESEÑAS BIBLIOGRÁFICAS}


